\title{
THE SYNCHRONIZATION OF HUMAN DIMENSION FACTORS IN DETERMINING MILITARY COMMAND CLIMATE
}

\author{
S.Inderjit \\ S. Ananthan, \\ Norshima ZS \\ FW Kwong \\ National Defence University of Malaysia, Kem Sungai Besi, Kuala Lumpur
}

\begin{abstract}
Military combat readiness has well-established procedures for gauging the preparedness of units for deployed combat operations. Such readiness evaluations typically include assessments of unit level tactical proficiency, equipment serviceability checks, manning levels, audits of logistic stocks and supply processes, and reviews of each unit member's individual readiness status. This health diagnosis prescribed as command climate looks only at the tangible quantitative factors which can be predetermined prior to combat duties. The intangible human dimension factor encompasses the morale, physical, and cognitive components of soldier, leader, and organizational development and performance. This is essential to raise, prepare, and employ the military in full spectrum operations which are not measured to complement the combat readiness factors. Despite recognition by military leaders throughout history that the human dimensions of capability are crucial to operational effectiveness, formal assessments of the psychological aspects of readiness appear to be the exception rather than the norm in today's military forces. Technology can provide the tools and avenues by which wars are fought but it is the individual soldier on the battlefield facing life and death who remains a constant.This paper looks at the literature on the synchronization on all the human dimension factors to complement the combat readiness to establish the combat command climate of a military organization. The paper promulgated that there is a need for quantitative assessment through questionnaires in all the human dimension factors which must be tabulated to individuals in organizations which includes a scoring worksheet to indicate the level of readiness both combat and human dimension readiness before being deployed for military combat duties.
\end{abstract}


Keywords: Human Dimension, command climate, combat readiness, morale, cognitive and physical dimensions, military culture

\section{Introduction}

The military cannot afford to focus only on current operations as a predictor of the future. It must prepare people so that future commanders can sustain operations in a time of persistent conflict. In spite of the amazing advances in technology, however, organizations continue to be plagued by ineffectiveness caused by flawed human (group) processes. Notwithstanding, the human dimension, not technology, remains the decisive element in most commercial and military activities. Judgment, creativity, and the synergy of teams remain a distinctly human phenomenon. Research shows that capability, especially in military organizations does not only relate to infrastructure capability but also includes intangible elements such as morale and motivation of soldiers in performing a military mission [1, 2,3,4]. In the military culture, soldiers often go beyond that which is needed, required, or expected in the performance of their duty or in other words, go beyond the call of duty. Furthermore, serving in the military is not just a career or a profession, but also a way of life that affects all aspects of soldiers' lives.

Faced with the demanding, all-consuming obligations, commitments, and sacrifices required by the Army, soldiers experience the challenge of balancing military work requirements and lifestyle with family and personal needs. The desire in military duties requires the tangible quantitative factors and the intangible human factors in cognizance to achieve both the desired results individually and collectively.

The US Army began in the early 1970s to investigate whether human dimensions and psychological readiness are important for combat performance [5]. It was reported that trends towards increased violence and isolation on the battlefield have led military planners around the world to place increased emphasis on the psychological and human dimensions of force readiness [6]. Significant research on morale has been conducted by the Israeli Defence Force. The first study was done by Guttmann [7] in 1949. He assessed soldiers' satisfaction with "arrangements" in their bases and their "mood" [8]. Guttman's term "mood" is most probably a substitute term for morale and the analysed data from a morale survey administered during 1981 in the Golan Heights [9]. During the late nineties a research on perceived combat readiness was conducted to ascertain the relationship between morale and combat readiness of soldiers [10].

This paper looks at the literature on the synchronization on all the human dimension factors to complement the combat readiness to establish the combat command climate in a military organization. The current 
Situational Force Scoring (SFS) which is the established tool in measuring tangible and quantitative requirements for combat duties will not be accounted for in this paper. The human factors needs to perform in concert to assist the commanding officer to establish the readiness of the soldier and his unit in general to complement the combat readiness of a military organization. They are needed to quantify the readiness of the unit prior to combat engagement. This paper will look at the human dimension factors of soldiers in meeting the challenges of the current and future operating environment in the moral, physical and cognitive domain in congruence to the man, machine interface whereby leadership skills will provide the major challenge. A climate assessment will be discussed using the best practices of command climate of established armies to spearhead this assessment from an individual soldier leading to a collective valuation of the unit in particularly the Malaysian Army.

\section{Military Culture in Combat Readiness}

Every organization has its own unique organizational culture, which directly and indirectly affects and influences all aspects of the organization [11]. The military provides the foundation and platform for soldiers with the logistic support merging into the high technological advances in the defence industry to perform in military duties. The military culture trains soldiers to perform in all conditions and the comradeship is essential in performing their duties. Modern military forces are concerned with the survival and effectiveness of their soldiers on the battlefields of today and tomorrow, and that are constantly concerned with integrating human and technical systems. This distinct culture consists of a variety of inherent, implicit and explicit functions, processes, characteristics, and manifestations that dynamically unite an organization [12]. What factors propagate this attitude or behavior and this exemplification of devotion, dedication, and selfless service? In particular, what drives soldiers' sense of duty, loyalty, and commitment, influencing their attitude and behavior and ultimately, duty performance? Within the South African context,indicates that faith, good morale and leadership, motivation, organizational and command cohesion, group norms and culture are important for success in battle [13]. "Culture is usually defined as social or normative glue that holds an organization together" [14] (1983, p. 344). An organization's culture, which is based on shared commonalities, creates an organization's context, establishing the framework for how it exists. The shared commonalities, such as values, meanings, and understandings, derive and perpetuate formal and informal structures and relationships, operational practices and procedures, collective values and beliefs, norms, and patterns of behavior [15, 16]. Holistically, the organizational culture propagates a shared frame of reference and the 
organization's shared reality, establishing a means by which people see and understand the happenings within their organization $[17,18]$.

The concept "combat readiness" is characterized by a proliferation of definitions. The evidence for readiness is mixed because of different definitions for readiness being used in the major surveys [19]. Some of the definitions by various academicians are as shown in Table 1.

\begin{tabular}{|c|c|}
\hline DEFINITION OF COMBAT READINESS & AUTHOR \\
\hline $\begin{array}{c}\text { A psychological attribute in terms of a soldier's choice or degree } \\
\text { of commitment to, and persistence in effecting a } \\
\text { certain course of action }\end{array}$ & Gal (1986) \\
\hline $\begin{array}{l}\text { "Combat readiness" acts as an inadequate bridge between } \\
\text { motivation and morale within the military context }\end{array}$ & $\begin{array}{l}\text { Lord Moran’s statement } \\
\text { (cited in Richardson, } \\
\text { 1978) } \\
\end{array}$ \\
\hline $\begin{array}{c}\text { Conceptualised the term "human readiness for combat” in terms } \\
\text { of three variables, namely Individuals’ Mental Readiness, Unit } \\
\text { Readiness, and Actual Performance in Combat. }\end{array}$ & $\begin{array}{c}\text { MacDonough and } \\
\text { Blankinship (cited in } \\
\text { MacDonough, 1991) } \\
\end{array}$ \\
\hline $\begin{array}{l}\text { Combat readiness as the concept as the state of preparedness of a } \\
\text { unit to perform its assigned role }\end{array}$ & $\begin{array}{c}\text { Ministry of Public } \\
\text { Works and Government } \\
\text { Services of Canada } \\
\text { (1997) }\end{array}$ \\
\hline $\begin{array}{l}\text { Combat readiness as the measure of a force conducting } \\
\text { operations successfully against a hostile force. }\end{array}$ & Lutz (1997), \\
\hline $\begin{array}{c}\text { Generalship, leadership, operational and tactical planning and } \\
\text { execution, logistics, intelligence and a host of other factors are } \\
\text { critical for combat performance }\end{array}$ & Hooker (1998) \\
\hline $\begin{array}{l}\text { Combat readiness as a grocery list for war with quantifiable items } \\
\text { that can be tallied, bought and paid for }\end{array}$ & Summers (1998) \\
\hline $\begin{array}{l}\text { Combat readiness in the US Army is measured by resources such } \\
\text { as soldiers, leaders, equipment, ammunition and fuel. These } \\
\text { resources, however, simply enable readiness and have always } \\
\text { been an inadequate yardstick for readiness. Therefore he argues } \\
\text { that the moral dimension should also be included }\end{array}$ & Rosenberger (1999) \\
\hline
\end{tabular}

Table 1: Various Definition of Combat Readiness by Academicians.

The current combat readiness is measured through the Situational Force Scoring (SFS) whereby their objective is to improve the representation of ground force close combat in aggregate combat models that use scores of one form or another to compute force ration, attrition and movement as a result of combat [20]. But this method does not measure the intangible factors of human dimension to synergize the unit readiness. SFS seeks to accomplish the first objective by adjusting the scores dynamically to reflect of the type of terrain, type of battle, and combined arms imbalances or shortages of each side's effective forces scores. The SFS methodology significantly mitigates many long standing problems of aggregate models such as their underestimating the relative value of light units even in 
situations where they are in fact highly effective, even more effective than armoured units [21].

Two aspects of combat readiness can be identified which is the psychosocial dimension (psychological attributes) and the material dimension (e.g. the number of tanks and their serviceability, the availability of ammunition). Various authors emphasize the importance of the psychosocial dimension (the human factor)in battle and during deployments $[20,21,22,23,24,25,26,27]$. This view is expressed in the United States Department of the Army's Field Manual 100-1 , which states that the readiness of a military force owes as much to the soldiers' state of mind as it does to his training and operational equipment. The process of looking at the material and training only is a mechanistic and structured process. Individual soldiers may have the best equipment and may receive the best training possible, but if they do not have confidence or trust in their abilities, equipment, personnel and training, their mission is most likely to fail. Therefore, it can be concluded that combat readiness is not only about equipment, training and capability, but more importantly, it is about the individual's and the group's state of mind. This state of mind includes their perception of their own combat readiness. In other words, combat readiness consists of two interdependent dimensions: the Psychosocial Dimension and Material Dimension. The confirmation of this interdependency indicatesthat motivational factors are interactive and not additive [30]. Combat readiness is therefore conceptualized in terms of an overlap between the psychosocial aspects (mental or human aspects) and the means at the disposal of the soldiers to conduct war (non-human aspects).

The focus of this paper is, however, being on the psychosocial aspects. The non-human indicator of combat readiness, such as the physical serviceability of military equipment,is not part of this study. Therefore, it is important to measure the soldiers' perceptions of the various building blocks. The following definition of combat readiness is proposed: the individual and/or collective state of mind of a soldier or a group of soldiers that will determine their performance during military operations. This state of mind is a function of the social trust and confidence these soldiers have, their worries and concerns, their familiarity with the enemy and the frontage, morale, and preconceptions of the opposing force. Confidence, social trust and morale are made up of various building blocks. Combat readiness can be conceptualised in terms of consisting two interdependent dimensions i.e. the tangible and intangible elements. Table 2 provides a list of some of the research and studies done on these elements and variables in the various domains. 


\begin{tabular}{|c|c|}
\hline VARIABLES & AUTHORS \\
\hline \multirow{5}{*}{$\begin{array}{c}\text { Nombat } \\
\text { Readiness } \\
\text { (1980), Saaty (2008), United States Department of Defence (2010), } \\
\text { Malaysian Army (2011), Griffith (2002), Wolosin, Wilcove \& Schwerin } \\
\text { (2003), Malaysian Armed Forces (2010), Moore (1991), Mumford (1976), } \\
\text { Bester and Stanz (2007), Filjak and Dencic (2005), Goyne (2004), Meijer } \\
\text { and Vries (2005), Knorr (1970), Clausewitz (1874), Griffith (1971), Paret } \\
\text { (1989), Australian Army (2008). }\end{array}$} \\
\hline \multirow{5}{*}{ Mapability } & $\begin{array}{c}\text { Andrews and Shambo (1980), Norazman (2000), Shafritz et al. (1989), } \\
\text { Luman (2000), Voith (2001), Zanella (2012), Australian Army (2008), } \\
\text { Malaysian Army (2010), United States Army (2008), Malaysian Army } \\
\text { (2011), Malaysian Armed Forces (2010). }\end{array}$ \\
\hline $\begin{array}{c}\text { Bester and Stanz (2007), Gal (1986), Schumm et al. (1996), Goyne (2004), } \\
\text { Cartignani (2004), Johnston, Brown, Cole \& Agrawal (2002), Riley } \\
\text { (2002), Murphy and Farley (2000), Knorr (1970), Siebold (1999), Britt, } \\
\text { Castrol and Adler (2006), Shamir et al. (2000), Gal and Manning (1987), } \\
\text { Snider and Watkins (2000), Baynes (1987), Slim (1956), Morgenthau } \\
\text { (1978), Buzan (1983). }\end{array}$ \\
$\begin{array}{c}\text { Rath and Harter (2010), Rice (1984), Blishen and Atkinson (1980), } \\
\text { Verwagen (1980), Zapf (1980), McKennell (1978), Kerce (1992), Kerce } \\
\text { (1995), Saris et al. (1996), Moller (1992), Campbell (1976), Andrews and } \\
\text { Withey (1976), Green (2001), Saaty (1994), Saaty (2008). }\end{array}$ \\
\hline
\end{tabular}

Table 2 - Variables and Authors Of Literature Review (Source Kwong,2013)

\section{The Human Dimension Characteristics ofa Soldier}

Many authors are of the opinion that Xenophon ${ }^{1}$ was the first military writer to give attention to soldier morale when he stated that it is not numbers and strength that bring victory to war, but the army that goes into battle "stronger in soul"; their enemies generally cannot withstand them. Maurice de Sac [31] stated twenty centuries later that the human heart is the starting point in all matters pertaining to war. A century later this was echoed by Napoleon's dictate that the moral is to the physical as three is to one, and in the end the Spirit will always conquer the sword [32,33]Du Picq's work introduced the notion of soldier morale and had, up to then, the widest influence over the development of military theory and speculation about combat behaviour [34]. In the early 1970s the US Army investigated whether human dimensions and psychologicalreadiness which are important for combat performance [35]. This led to the publication of Field Manual 100-5 (Department of the Army, 1983) which states that wars are fought and won by men, not by machines, and that the human dimension of war will be decisive in the campaigns and battles of the future [36].

There are broad definitions of psychological readiness that encompass factors such as physical and mental fitness, unit cohesion, commitment to the organisation, self-reported preparedness to deploy, and assessed technical competence (both job-related and broader military skills). However, this paper has adopted a simple definition: Individual readiness is 
the "extent to which an individual is prepared, able, and motivated to perform his or her job as part of the larger military mission" [37]. Collective readiness is the second critical dimension of psychological readiness: collective readiness. Just because the individual soldier may feel ready for operations dos not mean that he or she will feel the unit is ready and vice versa. Collective readiness refers to the individual soldier's beliefs about the ability of his or her work group or unit to be effective on operations. It is assumed often that the individual soldier's sense of his or her own operational readiness will predict or strongly influence their impression of the unit's readiness to deploy. However, there is evidence that perceptions of collective readiness are more likely to influence the soldier's own sense readiness than the other. This definition recognizes that soldier readiness everything from training proficiency to motivation to well-being is fundamental to the military's future success [38]. It introduces the concept of holistic fitness, a comprehensive combination of the whole person including all components of the human dimension triad. The Army leverages enhanced means to identify, access, retain, and develop soldiers with unsurpassed cognitive, physical, and social (moral and cultural) capabilities. Soldiers are enabled by technology, cognitive, medical and social sciences to achieve excellence in small unit competence and to dominate increasingly complex operational environments. Soldiers are able to leverage technologies and processes that optimize and restore cognitive and physical performance.

Technology, intelligence, and operational design can reduce uncertainty and ensure confidence. However, commanders must still make decisions based on incomplete, inaccurate, or conflicting information. These factors will continue to play a predominant role in the environment of future full spectrum operations. US Military Academy, Department of Systems Engineering, West Point conducted a research on the Whole Soldier Performance [39] which displays the final functional hierarchy of US soldier performance attribute groupings in the moral, cognitive, and physical domains as seen in Figure 1. 


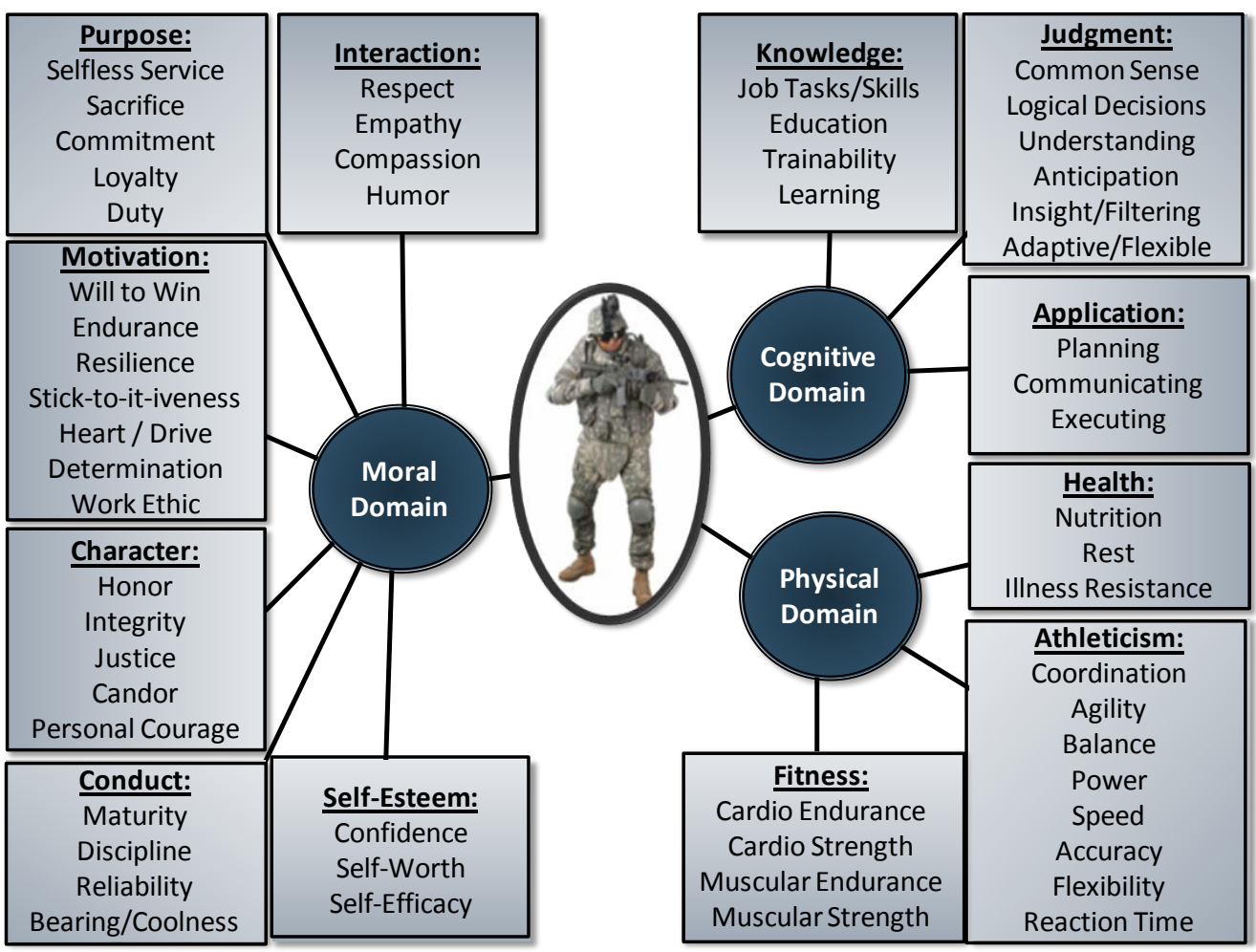

Figure 1. Whole Soldier Performance Attributes. (Source:Dees,2006)

The morale domain provides the recipe necessary for a soldier and his unit to perform in concert in a battlefield. All things being equal, the force with the best trained small units will win, but even if all is not equal, the side with the best skilled soldiers and determined small units will usually defeat larger and sometimes even better equipped units [40]. du Picq's work introduced the notion of soldier morale and had, up to then, the widest influence over the development of military theory and speculation about combat behavior [41].

Within the morale domain, the Army culture that previously focused on major combat operations must begin to shift to a culture that recognizes changes in the Army's role and responsibilities including a broader range of military operations [42]. Purpose relates to why a soldier does things. The main sentiment of those consulted centers around selfish versus unselfish attitudes. Motivation relates to the level of effort that soldiers demonstrate to accomplish the mission. Character relates to the manner in which soldiers accomplish the mission. Conduct relates to how soldiers carry themselves. We desire soldiers that display maturity and discipline leading to a balanced life. Interaction characterizes the attitudes that a soldier demonstrates towards other members of the team. The first level baseline expectation is 
that soldiers always display respect towards others. Self esteem characterizes the attitudes that a soldier holds concerning himself/herself [43].In the cognitive domain which is related to the cognitive psychology which is the branch of psychology concerned with the scientific study of the mind.The mind creates and controls mental capacities such as perception, attention, and memory, and creates representations of the world that enable us to function [44]. The simple vs. choice reaction time [45] and the forgetting curve for nonsense syllables [46] are examples of early experimental research on the mind.Because the operation of the mind cannot be observed directly, its operation must be inferred from what we can measure, such as behavior or physiological responding. Knowledge refers to the information possessed by soldiers and their ability to assimilate additional information. Relating to the information currently possessed, we desire soldiers that have a mastery of their specific job tasks and a strong basis in general Judgment refers to a soldier's ability to effectively process information and make logical decisions. With the information they have, soldiers should understand what is relevant, filter out the irrelevant, and gain insight into situations through a systematic thought process. Applicationrefers to a soldier's ability to translate decisions into effective actions. Once a decision has been made, we desire soldiers that can develop a plan to accomplish the desired end state. In the physical domain, fitness indicates that soldiers are fit in the traditional sense of the word [47]. In academic settings, this is referred to as the health-related components of fitness. These components are somewhat measured with the current Army physical fitness test and include cardiovascular and muscular endurance and strength [48]. Athleticism can be considered functional fitness, and was consistently the first set of attributes mentioned in the physical domain during our consultation. Health indicates that soldiers maintain their bodies in accordance with well-known principles of rest and nutrition. Nutrition and rest play major roles in energy levels, resistance to illness, and body composition.The human dimension is described as the "moral, cognitive, and physical components of soldier and organizational development" and states that "Army concepts acknowledge the soldier as the centerpiece of the Army, but none, individually or collectively, adequately addresses the human dimension of future operations." [49]. Within the context of the expected future global operating environment, this study looks in depth at expected soldier performance in the moral, physical, and cognitive domains.

\section{Command Climate Profile}

Command climate is a perception among the members of a unit about how they will be treated by their leaders and what professional opportunities they see within the unit. Command climate will determine the health of your 
unit. These will the elements which contribute to a positive command climate. The deployment of units in the Malaysian Army needs to be confounded by answering the questions of "Are the troops ready for combat duty". How do we measure such intangible factors such as the leadership style, welfare, morale, team work, unit cohesion, mind set and other components which provide a dimension together with tangible factors required for combat duties such as manpower issues, logistics and trained personnel. At such a profiling on soldiers' working climate need to be determined so that military leaders at all level is able to leverage the status of the soldiers in relation to their working environment [50]. The key to a positive command climate is credibility of the commander, communication, trust, and confidence. Keeping this in mind, command climate is a state or condition existing from shared feelings and perceptions among soldiers about their unit, about their leaders, and about their unit's programs and policies. This condition is created by the commander and his chain of command from the commander's vision and leadership style, and influenced and perpetuated by their communication and their leadership

In this era of persistent conflict, a unit's command climate is vital to long-term success at all levels of war in tactical, operational and strategic. Command climate is the culture of a unit. It is the way a unit "conducts business." The leader of the organization is solely responsible for the organization's command climate. Commanders at all levels establish this climate by what they say and what they do. Character-based leadership is the bedrock requirement for a successful command climate.Unit "climate" factors such as cohesiveness, morale, and attitude toward training have a direct impact on the effectiveness of a military unit.The earliest examples of a unit morale survey were produced by Lewis Guttman in the newly formed Israeli Army in 1949 [51]. Guttman's original questionnaire looked at basic concerns such as satisfaction with barrack living conditions and arrangements, etc [52]. However, as the Israeli Defence Force (IDF) became increasingly embroiled in combat actions throughout the region, combat readiness became the primary focus of morale related research. The work undertaken using Combat Readiness Morale Questionnaire (CRMQ) was instrumental in identifying the core factors that determine personal and unit level morale for fighting troops [53]. He conducted a factor analysis on the CRMQ results of over 1200 IDF troops about to engage in a 'contingent operation' in Lebanon in 1981 [54]. He found two items in particular were highly associated with personal and perceived company morale, 1) perceived unit togetherness and 2) relationships with commanders. In addition, a factor analysis of the 30 items in the questionnaire revealed eight factors that accounted for $52 \%$ of the variance for his sample, including 1) confidence in senior commanders, 2) confidence in one's self, team and weapons, 3) unit 
cohesion and morale, 4) familiarity with the mission and frontage, 5) confidence in immediate commanders, 6) enemy evaluation, 7) the legitimacy of the war, and 8) worries and concerns. As a result of this work the term 'unit climate' to describe a higher-order factor that appeared to be a better predictor of combat readiness than morale alone [55].

While preparing for combat is still the major focus of research into the human component of military effectiveness [56], it is not the only concern for commanders. This is especially true in certain countries where the majority of military units are not engaged directly in combat actions. Additionally, even though an increasing number of personnel are being deployed on missions overseas, the nature of those missions is rarely direct combat. Consequently, while unit commanders are always concerned about the preparation of their troops for battle, their main priorities are more likely to be stemming the flow of resignations, preventing inappropriate behaviour, or ensuring the effectiveness of communication in the unit [57]. This shift in priorities does not diminish the importance of combat readiness but addresses the reality of peace time soldiering. The importance of organisational issues is reflected in the US Army Command Climate Survey [58]. The CCS focus on practical concerns that fall within the unit commander's power to change (e.g., morale, leadership and equity issues). The CCS is designed to be administered, analysed and interpreted by the CO without recourse to any outside agency. It is also a mandatory requirement for newly appointed COs both at the beginning of their command and twelve months after taking up their post. There is no normative data for the CCS, but given that the results of the first administration of the survey largely provide a baseline for an incoming $\mathrm{CO}$, the true measure of the COs leadership and impact on the unit is gauged at the 12 month point. The CCS is an example of an attitude survey and the main advantages of this type of instrument are that they are short, easy to administer, and COs can quickly gain a measure of the views of their troops without requiring any particular interpretation [59].

Since 1996, the Canadian Forces have been administering the Human Dimensions of

Operations survey to Canadian Forces personnel deployed on Peace Support operations.Measuring dimensions such as morale, cohesion, confidence in leadership and stress, amongstothers, the Human Dimensions of Operations survey provides Commanding Officers with a toolto measure and monitor important human dimensions that affect operational readiness andeffectiveness of deployed units [60]. In developing the model, which is not conclusive, and continues to undergo review as data is gathered and analyzed, emphasis was placed on predictors, effects and outcomes associated with unit effectiveness with each examined across three levels: 
organizational, group and individual. This model has formed the basis for the development of the Unit Morale Profile. The UMP was designed to explore the relationships between a number of variables and outcomes such as resignations and perceived satisfaction in the unit. The questionnaire comprised 14 sub-scales which not only measured the causes of problems within a unit but also measured the effects (e.g, cohesion, organizational commitment, quality of life, and psychological wellbeing), and outcomes (e.g, perceived satisfaction with group performance and plans to leave the organisation). The UMP measures 14 dimensions namely role stress, work motivation, job satisfaction, psychological distress, quality of life leadership style, confidence in leadership, cohesion, communication, climate, preparedness for deployment, perceived organizational support and organizational commitment, job performance, retention/attrition [61]. While extremely comprehensive the UMP was clearly too long and cumbersome for use on the ground, and a major review was undertaken to shorten the instrument [62].

As a result a new streamlined version, known as the Profile of Unit Leadership, Satisfaction and Effectiveness (PULSE) produced by the Australian Defence Force (ADF) eventually replaced the UMP. With the introduction of the Profile of Unit Leadership Satisfaction and Effectiveness (PULSE) in 2004, Australian commanders now have a tool available to measure a range of factors about their personnel [63].This instrument retained the underlying tri-level structure of individual, group and unit, but introduced a new dimensional structure comprising six core constructs as shown in Table 2

\begin{tabular}{|c|c|c|}
\hline VARIABLE & CONSTRUCTS & AUTHOR \\
\hline Job Stress & $\begin{array}{l}\text { Derived from the Occupational } \\
\text { Environment Scale - Form2 }\end{array}$ & $\begin{array}{c}\text { Osipow, \& Spokane, } \\
1983 \\
\end{array}$ \\
\hline Job satisfaction & Derived from the Job Satisfaction Survey & Specter, 1985 \\
\hline Work Motivation & The Work Motivation Scale & $\begin{array}{l}\text { Pelletier, Fortier, } \\
\text { Vallerand \& Briere, } \\
2003\end{array}$ \\
\hline Communication & $\begin{array}{l}\text { Derived from the Communication } \\
\text { Satisfaction Questionnaire }\end{array}$ & Downs \& Hazen, 1998 \\
\hline $\begin{array}{l}\text { Confidence in } \\
\text { Leadership }\end{array}$ & $\begin{array}{l}\text { From the Unit Climate Profile Human } \\
\text { Dimensions of Operations Questionnaire }\end{array}$ & ARI, 2006 \\
\hline Teamwork/Cohesion & $\begin{array}{l}\text { Derived from the Group Environment } \\
\text { Questionnaire }\end{array}$ & $\begin{array}{l}\text { Widmeyer, Brawley \& } \\
\text { Carron, } 1985\end{array}$ \\
\hline
\end{tabular}

Table 2. Profile of Unit Leadership, Satisfaction and Effectiveness (PULSE) Variables, Constructs and Authors

The purpose of this new model was to observe the linkages between each core construct, to provide an overall view of the climactic interrelationships operating within the unit as shown in Table 3 [63].In 
developing the UMP/PULSE the authors incorporated a number of scales developed within the industrial/organisational research community. As a consequence, the instrument requires a solid understanding of this theory to interpret effectively and is not immediately intuitive like an attitude survey.

\begin{tabular}{|c|c|c|c|}
\hline $\begin{array}{l}\text { The PULSE Model } \\
\text { Predictors }\end{array}$ & Indicators & Outcomes & $\begin{array}{l}\text { Level Of } \\
\text { Effect }\end{array}$ \\
\hline $\begin{array}{c}\text { Policies \& practices } \\
\text { Unit climate } \\
\text { Operation Tempo } \\
\text { Perceived organisation } \\
\text { support } \\
\end{array}$ & $\begin{array}{c}\text { Esprit de corps } \\
\text { Organisational } \\
\text { commitment } \\
\text { Organisational } \\
\text { satisfaction } \\
\end{array}$ & $\begin{array}{l}\text { Unit performance } \\
\text { Intent to leave } \\
\text { unit/ADF }\end{array}$ & UNIT \\
\hline $\begin{array}{l}\text { Leadership styles } \\
\text { Communication }\end{array}$ & $\begin{array}{c}\text { Group cohesion } \\
\text { Job satisfaction } \\
\text { Confidence in } \\
\text { leadership } \\
\end{array}$ & $\begin{array}{l}\text { Group performance } \\
\text { Intent to leave } \\
\text { working group }\end{array}$ & GROUP \\
\hline $\begin{array}{l}\text { Role stressors } \\
\text { Competencies }\end{array}$ & $\begin{array}{c}\text { Health } \\
\text { Motivation } \\
\text { Job satisfaction }\end{array}$ & $\begin{array}{c}\text { Individual } \\
\text { performance }\end{array}$ & INDIVIDUAL \\
\hline
\end{tabular}

Table 3: The Australian PULSE Model

The United Kingdom Armed Forces uses the Armed Forces Continuous Attitude Survey (AFCAS) as their instrument for organizational command climate. The MOD uses the Armed Forces Continuous Attitude Survey (AFCAS) to collect information on the attitudes, opinions and circumstances of serving personnel. The main report of the AFCAS includes tables of response data for all of the survey's questions and full details of the conduct and analysis of the survey.

\section{Synchronization of Human Dimension Factors For Command Climate Assessment}

This research is seeking a set of instrument to measure such intangible cognitive factors to complement the tangible combat readiness for units to be deployed. The research will identify and synchronize all intangible factors influencing command climate of a Malaysian Army Brigade and Battalion. This is by developing a validated and reliable instrument to measure command climate in the Malaysian Army. The outcome is designing a scoring worksheet to determine status of command climate in unit. This instrument will also take preventive measures and also corrective measures after establishing the score of an individual, unit and an organization. The Improved Man-Machine Interfaces research area is motivated by the fact that technology designed to enhance soldier performance often imposes both physical and cognitive stress on the soldier in ways that equipment developers do not envision. Specifically, this paper focuses on understanding the interaction between physical and cognitive 
stress and their effect on individual dismounted soldier and small team performance. The assessment needed to undermine the intangible human factors for this research will focus on the morale factors which will be seeking the elements of the moral component.Elements of the morale component: The Warrior Spirit, with its moral-ethical foundation, and sociocultural awareness. The morale component strongly relates to the physical and cognitive components of the human dimension. The moral component directly affects the Army's combat effectiveness. Spirit, as used in this concept, is that intangible sense of self and of purpose, which provides drive and motivation. Spirit is what an individual athlete or team possesses that somehow enables them to triumph over others in competition [64]. The Army places great emphasis on its proud heritage of selfless service, discipline, the wear and appearance of uniforms, customs of the Service, values, and teamwork to build esprit de corps and cohesive teams and units. Developing the human spirit includes self-reflection and self-awareness, and individual assumption of responsibility for developing a broad concept of a meaningful life, faith, and social awareness.Faith is the strong belief in what constitutes ultimate truth or value. One of the world's religions provides the basis for the faith of many soldiers. Though not everyone finds faith through religion, most people develop some level of faith in a person, philosophy, an institution, or a nation. Morale is an intangible, dynamic characteristic that strengthens confidence in oneself, one's equipment, the unit, and the unit's leadership [65]. Morale generally consists of common purpose, identity with, and a personal commitment to a unit; and confidence, enthusiasm, and persistence within a military framework. High morale is a characteristic of effective units.

The determinants of morale are both individual and group-related, reflecting their interdependence with unit cohesion and esprit de corps. The characteristics and perceived legitimacy of the mission affects morale. Mission factors become especially important in operations whose purpose, objectives, definitions of success, and duration change over time, but nothing has a greater influence on morale than perceived success in accomplishing the mission. Living conditions and rations naturally concern soldiers. Leaders must balance efforts to provide creature comforts with maintaining fighting fitness and accomplishing the mission. The Army must continue to provide the best possible care and living conditions to the Soldier now and in the future, but never at the expense of the mission. Esprit de corps and cohesion, while less tangible than weapons systems, can prove the old axiom of the whole being greater than the sum of its parts. In a military context, cohesion is the bonding of soldiers within their organizations their morale, will to fight and commitment to each other, the unit, and mission accomplishment. Like morale, esprit de corps is a dynamic relationship 
whose strength is dependent on many factors.Unit cohesion aids commanders in establishing the environment to anchor individual morale. Unit cohesion will help to extend the reach and coverage of units. Primary cohesion has two components: horizontal, or peer bonding, and vertical, or soldier to leader, bonding. Military group cohesion develops beyond just primary groups at four interrelated levels: peer (horizontal), leader (vertical), organizational (battalion, regiment) and institutional (Army). Building cohesive units is important today and in the future, because it contributes to building and maintaining morale and because it enhances unit performance and reduces discipline problems. There is currently no instrument to measures such intangible factors in the Malaysian Army and there is a need to look at other armies such as from US, UK, Australia and Canada to design a set of questionnaires correlated with a scoring worksheet to determine the combat readiness of the unit. There is a need to create a validated and reliable instrument that can measure such intangibles to provide Brigade/Battalion Commanders and top management of the Army a clear and unified picture of unit combat readiness and effectiveness.

\section{Conclusion}

Command (organizational) climate has become an increasingly significant prerequisite for unit effectiveness and combat readiness as shown by many established armies all over the world. While many Army units enjoy positive command climate, too many do not. Several adverse trends in command climate have persisted in the Army for nearly 30 years (since the end of the communist terrorist threat). Command climate is one of the most observed and least understood concepts in the military. A goal of every commander today is a healthy command climate and a cohesive unit. The human dimension encompasses the moral, physical, and cognitive components of soldier, leader, and organizational development and performance essential to raise, prepare, and employ the Army in full spectrum operations. Army concepts acknowledge the soldier as the centerpiece of the Army, but none, individually or collectively, adequately addresses the human dimension of future operations. The soldier performance attribute groupings in the moral, cognitive, and physical domains provides a platform for the intangible factor needed in the human interface in man machine method. The machine is just a tool for the soldier in battlefield and the tactics is the method but overall the soldier is the platform using all his training in cognitive reasoning in making significant decisions in the battlefield whereby the machine an method is just the psychomotor aspect in assisting him meet his goals. The objectives of this study are to provide an 'audit trail' of the rise of the command climate concept in hopes of arriving at an understanding of the idea; discuss its 
recognition, controversial nature, purpose, application and linkage; review the awareness and acceptance problem; identify existing means of evaluating the concept; suggest ways of improving a unit's command climate; and last, make several conclusions and recommendations about command climate. It is recommended that this study be reviewed by The Malaysian Army Training Division, Army Human Resources Department and other Leadership Divisions; shared with future commanders at the Pre command Course; and considered for publication Army-wide.

\section{References:}

Bester, P.C., \& Stanz, J.K. (2007). The conceptualization and measurement of combat readiness for peace support operations- an exploratory study. SA Journal of Industrial Psychology, 33 (3), 68-78.

Gal, R. (1986).Unit morale: From a theoretical puzzle to an empirical illustration - An Israeli example. Journal of Applied Social Psychology, 16(6), 549-564.

Schumm, W.R., Bell, D.B., Rice, R.E. \& Schuman, P.M., (1996). Marriage trends in the US Army. Psychological Reports, 78: 771-784.

Norazman bin Mohamad Nor, (2000). The modelling of defence structure for long term planning under financial constraint: A complex army restructuring process for a third world country (Unpublished Doctoral thesis).

Kirkland, F.R., Bartone, R.T. \& Marlowe, D.H. (1993). Commander's priorities and psychological readiness. Armed Forces \& Society, 19(4): 579598.

Batone, P.T. \& Kirkland, F.R. (1991). Optimal leadership in small army units. In R. Gal \& A.D. Mangelsdorff (Eds), Handbookof Military Psychology (pp.507-530). New York: John Wiley \& Sons.

Gal, R. (1986).Unit morale: From a theoretical puzzle to an empirical illustration - An Israeli example. Journal of Applied Social Psychology, 16(6), 549-564

Gal, R. (1986).Unit morale: From a theoretical puzzle to an empirical illustration - An Israeli example. Journal of Applied Social Psychology, 16(6), 549-564

Gal, R. (1986).Unit morale: From a theoretical puzzle to an empirical illustration - An Israeli example. Journal of Applied Social Psychology, 16(6), 549-56

Shamir, B., Brainin, E., Zakay, E., \& Popper, M. (2000). Perceived combat readiness as collective efficacy: Individual- and group-level analysis. Military Psychology, 12(2), 105-119.

Yukl, G. (2002). Leadership in organizations (5th ed.). Upper Saddle River, NJ: Prentice Hall. 
Rush, R.S. (1999). A different perspective: Cohesion, morale, and operational effectiveness in the German Army, fall 1944. Armed Forces and Society, 25(3): 477-508.

De Vries, R. (1993). The military tactical appreciation - sharpening the psychological combat edge. Armed Forces, March.

Smircich, L. (1983). Concepts of culture and organizational analysis. Administrative Science Quarterly, 28 (3), 339-358. Retrieved February 5, 2005, from EBSCO Host Business Source Premier database.

Morgan, G. (1997). Images of organization (2nd ed.). Thousands Oaks, CA: Sage Publications.

Schein, E. H. (1992). Organizational culture and leadership (2nd ed.). San Francisco, CA: Jossey-Bass.

Morgan, G. (1997). Images of organization (2nd ed.). Thousands Oaks, CA: Sage Publications.

Schein, E. H. (1992). Organizational culture and leadership (2nd ed.). San Francisco, CA: Jossey-Bass.

Schumm, W.R., Bell, D.B., Rice, R.E. \& Schuman, P.M., (1996). Marriage trends in the US Army. Psychological Reports, 78: 771-784.

Allen, Situational Force Scoring:Accounting For combined Arms Effects in Aggregate Combat Model RAND,N-2625-NA,July 1987.

Allen,Patrick, and Barry Wilson, Secondary Land theater Model,RAND,N2625-NA,July 1987.

Baynes, J. (1967). Morale: A study of men and courage. London:mCassell.

De Vries, R. (1993). The military tactical appreciation - sharpening the psychological combat edge. Armed Forces, March

Flora, C.B. (1992). Book reviews. Armed Forces \& Society, 19(1):139- 160.

Gal, R. (1986).Unit morale: From a theoretical puzzle to an empirical illustration - An Israeli example. Journal of Applied Social Psychology, 16(6), 549-564.

Hooker, R.D. (1998). Building unbreakable units. Retrieved June 02, 2001 from the World Wide Web:

http://www.usafa.af.mil/jscope/JSCOPE98/HOOK98.HTM.

Shay, J. (2000). Preventing psychological injury in military service.Boston: Department of Veteran Affairs Outpatient Clinic and Tufts Department of Psychiatry. Retrieved May 24, 2001 from the World Wide Web: http://belisarius.com/umodern_business_strategy/shay/shay_

prevent_psy_injury.htm.

Taylor, A.J.W. (1991). Individual and group behaviour in extreme situations and environments.

Vinson, M.E. (2000). Structuring the army for full-spectrumreadiness. Parameters, $\operatorname{xxx(2):~19-32.~}$ 
Gal, R. (1986).Unit morale: From a theoretical puzzle to an empirical illustration - An Israeli example. Journal of Applied Social Psychology, 16(6), 549-564.

Manning, F.J. (1991). Morale. Cohesion and esprit de corps. In R. Gal \& A.D. Mangelsdorff (Eds), Handbook of Military Psychology (pp.507-530). New York: John Wiley \& Sons.

Manning, F.J. (1991). Morale. Cohesion and esprit de corps. In R. Gal \& A.D. Mangelsdorff (Eds), Handbook of Military Psychology (pp.507-530). New York: John Wiley \& Sons.

Richardson, F.M. (1978). Fighting spirit: A study of psychological factors in war. London: Leo Cooper

Brown, C.W. \& Moskos C.C. (1976). The American volunteer soldier: Will he fight? Military Review. Retrieved June 12, 2001 from the World Wide Web: http://160.149.101.23/ milrev/english/janfeb97/browncw.htm.

Kirkland, F.R., Bartone, R.T. \& Marlowe, D.H. (1993). Commander's priorities and psychological readiness. Armed Forces \& Society, 19(4): 579598.

FM 100-5 1983,Operations.Army Field Manual,Washington, D. C: Department of Army Field Manual

Harris, J. H., Blair, M. D., \& O’Neill, H. M. (1995). MWR programs and readiness links. Fairfax, VA: Caliber Associates.

Department of the Army (1986, May) Operations (FM 100-5). Washington. DC.

MAJ Rob Dees. Whole Soldier Performance: A Value-Focused Model of Soldier Quality, USMA Department of Systems Engineering,West Point, NY 2006

Kruys, G.P.H. (2001). Combat readiness with specific reference to armies. In M. Hough \& L. du Plessis (Eds), Selected military issues with specific reference to the Republic of South Africa (pp.87-105). Pretoria: Institute for Strategic Studies.

Brown, C.W. \& Moskos C.C. (1976). The American volunteer soldier: Will he fight? Military Review. Retrieved June 12, 2001 from the World Wide Web: http://160.149.101.23/ milrev/english/janfeb97/browncw.htm.

Abram, A. (2007, Spring). The philosophy of moral development. Forum Philosophicum;

International Journal for Philosophy. Vol. 12, No 1. Retrieved from http://www.forumphilosophicum. eu/issues.html

Carl A. Castro and Amy Adler, "Joint Medical Surveillance in Bosnia: Psychological Screening," US Army Medical Research Unit-Europe Technical Report, Heidelberg, Germany, 1999.

McKennell, A.C. (1978). Cognition and affect in perceptions of well-being. Social Indicators Research, 5, 389-426. 
B. Theunissen. Franciscus Cornelis Donders 1818-1889, F.C. Donders: turning refracting into science, @ History of science and scholarship in the Netherlands, 2010

Wozniak, R. H. (1999). Introduction to memory: Hermann Ebbinghaus (1885/1913).

Classics in the history of psychology

TRADOC Pamphlet 525-3-7-01. The U.S. Study of the Human Dimension in the Future 2015-2024. http://www.tradoc .army.mil/tpubs/pams/p525-3-701.pdf (accessed 2008). (Training and Doctrine Command [TRADOC], 2008).

Glassman, G. (October 2002). What is fitness? CrossFit Journal, available at http://library.crossfit.com/free/pdf/CFJ-trial.pdf.

TRADOC Pamphlet 525-3-7-01. The U.S. Study of the Human Dimension in the Future 2015-2024. http://www.tradoc .army.mil/tpubs/pams/p525-3-701.pdf (accessed 2008).(Training and Doctrine Command [TRADOC], 2008).

Moran, E. T., \& Volkwein, F. J. (1992). The cultural approach to the formation of organizational climate. Human Relations, 45(1), 19-47.

Gal, R. (1986).Unit morale: From a theoretical puzzle to an empirical illustration - An Israeli example. Journal of Applied Social Psychology, 16(6), 549-564.

Gal, R. (1986).Unit morale: From a theoretical puzzle to an empirical illustration - An Israeli example. Journal of Applied Social Psychology, 16(6), 549-564.

Gal, R. (1986).Unit morale: From a theoretical puzzle to an empirical illustration - An Israeli example. Journal of Applied Social Psychology, 16(6), 549-564.

Gal, R. (1986).Unit morale: From a theoretical puzzle to an empirical illustration - An Israeli example. Journal of Applied Social Psychology, 16(6), 549-564.

Gal, R. (1986).Unit morale: From a theoretical puzzle to an empirical illustration - An Israeli example. Journal of Applied Social Psychology, 16(6), 549-564.

Murphy, P.J., \& Farley, K.M.J. (2002). Morale, cohesion and confidence in leadership: Unit climate dimensions for Canadian soldiers on operations. In C. McCann \& R. Pigean (Eds.). The human in command: Exploring the modern military experience. New York: Kluwer Academic/Plenum Publishers.

Britt, T., Castrol, A., \& Adler, A. (2006). Military Life: The Psychology of Serving in Peace and Combat,Military Performance, 1: 162 
TRADOC Pamphlet 525-3-7-01. The U.S. Study of the Human Dimension in the Future 2015-2024. http://www.tradoc .army.mil/tpubs/pams/p525-3-701.pdf (accessed 2008). (Training and Doctrine Command [TRADOC], 2008).

Riley, M.A. (2002). Measuring the human dimension of unit effectiveness the Unit Morale Profile. Paper presented at the 38 International Applied Military Psychology Symposium, Amsterdam: The Netherlands.

Murphy, P.J., \& Farley, K.M.J. (2000). Morale, cohesion, and confidence in leadership: Unit climate dimensions for Canadian soldiers on operations. In, C. McCann, \& R. Pigeau

Murphy, P.J., \& Farley, K.M.J. (2000). Morale, cohesion, and confidence in leadership: Unit climate dimensions for Canadian soldiers on operations. In, C. McCann, \& R. Pigeau

Johnston, B.F. (2004a). The Unit Morale Profile a measure of organizational climate for the Canadian Forces. Unpublished presentation DHRRE.

Goyne,2003. Measuring Unit Effectiveness: What Do Commanders Want to Know and Why? Psychology Research and Technology Group.Australian Regular Army

Johnston, B.F. (2004a). The Unit Morale Profile a measure of organizational climate for the Canadian Forces. Unpublished presentation DHRRE.

Manning, F.J. (1991). Morale. Cohesion and esprit de corps. In R. Gal \& A.D. Mangelsdorff (Eds), Handbook of MilitaryPsychology (pp.507-530). New York: John Wiley \& Sons

Gal, R., \& Manning, F. (1987). Morale and its components: A cross national comparison. Journal of Applied Social Psychology, 369-391Kwong, 2013). Record of Proceedings,Statistics and Operational International Conference,Kuching 4 Dec 2013 